\section{Journal homepage:http://www.journalijar.com \\ Journal DOI:10.21474/IJAR01}

\section{RESEARCH ARTICLE}

INTERNATIONAL JOURNAL

OF ADVANCED RESEARCH

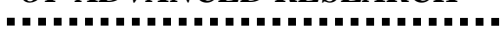

\title{
Improvement of Asphalt Binder by Recycling of Waste Tire Rubber
}

Ihsan Habib Dakhil

Chemical Engineering Department, College of Engineering, Al-Muthanna University, Al-Samawa, Iraq.

\section{Manuscript Info}

Manuscript History:

Received: 15 March 2016

Final Accepted: 19 April 2016

Published Online: May 2016

Key words:

Improvement, Asphalt binder, Recycling, Waste Tire, Rubber powder.

*Corresponding Author

Ihsan Habib Dakhil

\begin{abstract}
The aim of present work is to study improving of physical properties of AlBasra asphalt binder including softening point, penetration and ductility by adding powder of waste tire rubber (WTR) and to get optimum operating test parameters.

The effect of adding WTR on improvement asphalt binder had been carried out at different weight percent of WTR (0-30) wt $\%$ and mixing temperatureof $(150-230)^{\circ} \mathrm{C}$. The experimental results have been proven successful improvement physical properties of asphalt binder due to good interacting between particles of WTR and binder.

The optimum operating parameters were $20 \mathrm{wt} \%$ of WTR and $190{ }^{\circ} \mathrm{C}$ of mixing temperature.At optimum operating parameters tested, it can be observed that increasing WTR dosage lead to increasing the softening point and decreasing the penetration point and ductility values. On the other hand, the increasing of mixing temperature above $190{ }^{\circ}$ Caffected negatively on WTR properties.
\end{abstract}

Copy Right, IJAR, 2016,. All rights reserved.

\section{Introduction:-}

The use of waste rubber tires in pavement applications dates back to the early of the 1960's. The modification processes using rubber tires can be divided into two categories (dry process or wet process). Dry process when recycle rubber tire used as an asphalt mixture modifier and wet process when it used as asphalt binder modifier[Xiang and Baoshan, 2013].

Waste tire rubber is considered an attractive source for modification of asphalt because the process considered to be doubly effective solution for environmental pollution.First, it represents a cleaning way to dispose the waste tire and second, it is a good source for modification of physical properties of asphalt binder.To improve asphalt binder that possess a higher softening point and keeping minimum range of penetration and ductility at the same time [AlHadidy, 2006].

The aim of this workis to study the effectadding WTR on the physical properties of asphalt binder that produced from Al-Basra refinery/Iraq with different weight percentage of WTR (0-30) wt\% and mixing temperature range of $(150-230)^{\circ} \mathrm{C}$. The asphalt binder properties that evaluated were included test of softening point, penetration and ductility to find the optimum dosage of WTR and mixing temperature.

\section{Materials and Methods:-}

Asphalt binder that produced in Al-Basra refinery/Iraq has been used with penetration grade of (40-50). The physical properties of the samples have been tested before and after process treatment.

Waste tire rubber which is used as an additive with asphalt binder, it is collected from local markets then it waswashed several times and cut in small species after that it was converted into powder by grinding in mechanical grinder and screened using a sieve to get particle size range of (2-5) $\mathrm{mm}$. WTR was added to asphalt binder in different weights percent with varying mixing temperature.Two hundred grams of asphalt binder were heated to 
required temperature then poured into $500 \mathrm{ml}$ cylindrical flask which was placed on a magnetic stirrer $(150 \mathrm{rpm})$, the WTR dose was added gradually to prevent particles from agglomeration with mixing time of 2 hours.

Studying the effect addition of WTR on asphalt binder properties was performed by test of softening point, ASTM (D-36), test of penetration that is take place at $25^{\circ} \mathrm{C}$, ASTM (D-5), and ductility test that is take place at $25^{\circ} \mathrm{C}$, ASTM (113-99). Softening point and penetration point tests were measured of asphalt consistencywhereas ductility test was provided measure of asphalt binder tensile which used to measure flexibility of asphalt binder under various temperatures.

\section{Results and Discussion:- \\ Softening Point Test:-}

Fig.(1) shows the effect of adding different dose(0-30) wt $\%$ of WTR on softening point of binder at different mixing temperature (150-230) ${ }^{\circ} \mathrm{C}$. It can be seen the softening point increases with increasing WTR weight percent because of increasing molecular weight of binder. The optimum weight percent was $20 \mathrm{wt} \%$, After that, the softening point continuous in straight line. These results are agreement with finding of most researches such as Falaket al. (2008), Al-Hadidy (2006), Saad and Ibtihal (2014).

Fig.(2) shows the effect of increasing mixing temperature atoptimum dose of WTR of $20 \mathrm{wt} \%$ on softening point of binder. It can clear to notice that the softening point increases with increasing of mixing temperature till temperature of $190{ }^{\circ} \mathrm{C}$ which is represented the optimum temperature for mixing of WTR with asphalt binder. When WTR particles were adding to binder, the aromatic oils of the binder were absorbed into the particles of WTR, this physical absorption resulting swelling of WTR particles to three times of their original volumeand forming gelasphalt binder, this change in particle size causing an increasing in viscosity of binder. After that, the softening point was decreasing gradually this can be attributed to the particles of WTR were decomposed at temperature above 200 ${ }^{\circ} \mathrm{C}$ which causing reduction in binder viscosity. These results are agreement with finding of Zanzotto and Kennepohl (1996), Abdelrahman and Carpenter (1999) and Rahman (2004).

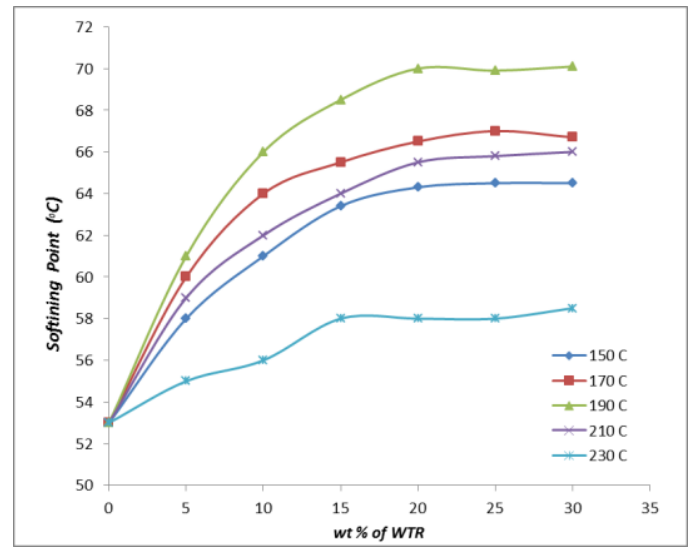

Figure (1) The effect of adding WTR at different mixing temperature on softening point.

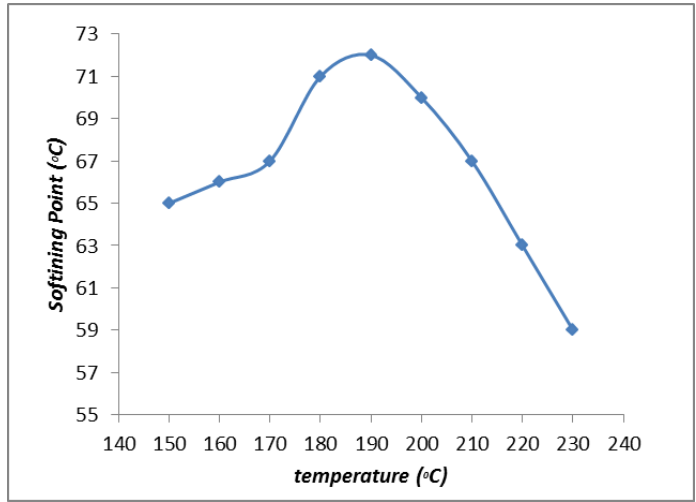

Figure (2) The effect of mixing temperature on softening point. 


\section{Penetration Test:-}

Fig.(3) shows the effect of adding different WTR weight percent of WTR (0-30) wt\% at different mixing temperature of $(150-230)^{\circ} \mathrm{C}$ on penetration. It is clear to see decrease penetration of binder with increasing of WTR content for all mixing temperatures tested due to increasing viscosity of binder. The optimum dose of WTR was happened after addition of $20 \mathrm{wt} \%$. After this point the penetrationcontinue approximate in the same degree. This observationis agreement with the results of many researches of Taheret al. (2009), Emanet al. (2011),Saad and Ibtihal (2014).

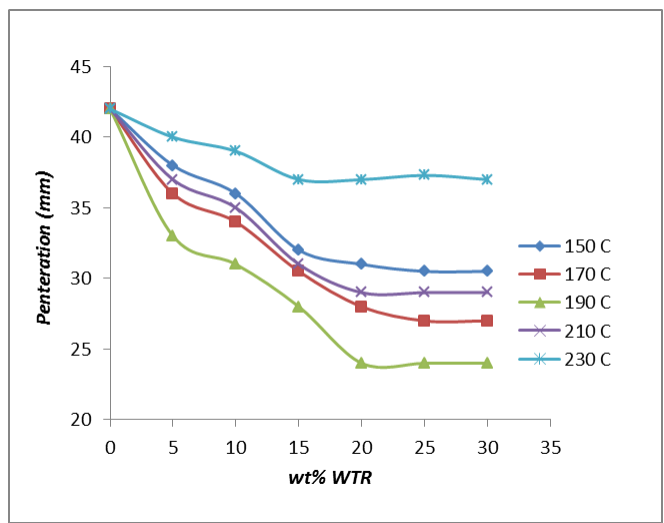

Figure (3) The effect of adding WTR at different mixing temperature on penetration.

Fig.(4) shows the effect of increasing mixing temperature at optimum dose of WTRat $20 \mathrm{wt} \%$. It can be seen the penetrationof binder decreases with increasing of temperature till $190^{\circ} \mathrm{C}$, after that the penetration increases with increasing of temperature. This result can be attributed to the breakdown of rubber chains at high temperature into small molecules which causing a reduction in viscosity of binder. A similar phenomenon was observed by Zanzotto and Kennepohl(1996),Al-Hadidy (2006), Xiang (2013) and Davide (2013).

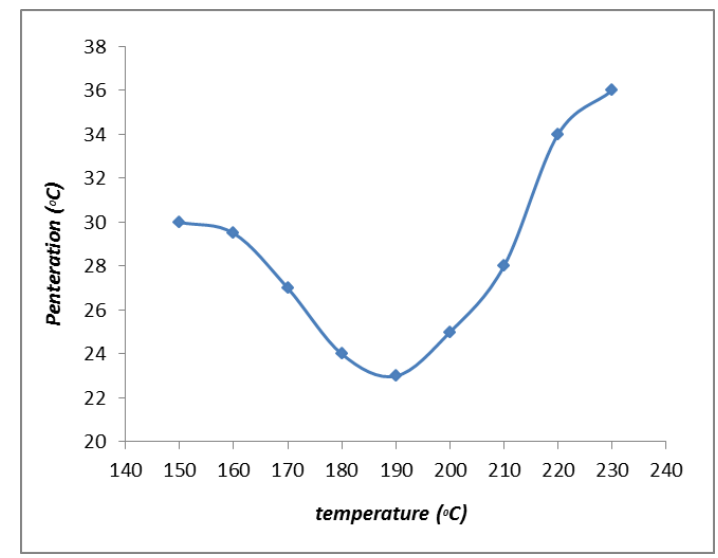

\section{Ductility Test:-}

Figure (4) The effect of mixing temperature on penetration.

The effect of adding different amount of WTR (0-30) wt $\%$ at various mixing of temperature on ductility of binder is shown in Fig.(5). The ductility of binder decreases with increasing of amount of WTR added due to increase of viscosity and elasticity properties of binder. This result is agreement with the most researchers of Al-Hadidy (2006), Emanet al. (2011) and Saad and Ibtihal (2014). 


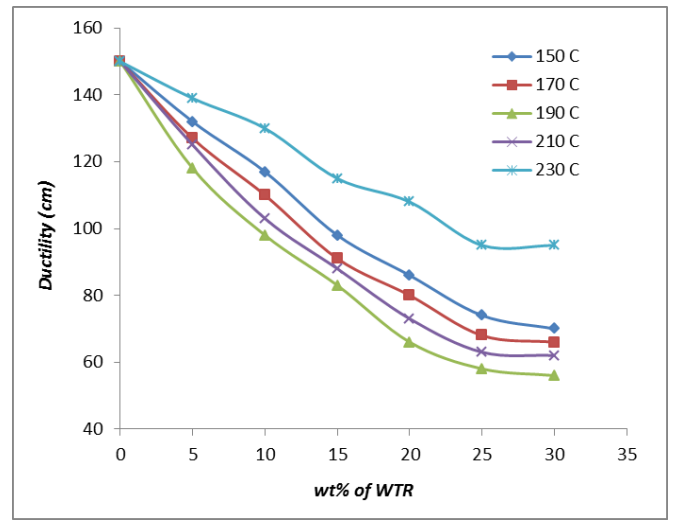

Figure (5) The effect of adding WTR atdifferent mixing temperature on ductility.

Fig.(6) shows the effect of varying mixing temperature at optimum WTR percent at $20 \mathrm{wt} \%$. It is clear to see the ductility of binder decrease in the range of $(150-190){ }^{\circ} \mathrm{C}$ which reach to $65 \mathrm{~cm}$. After mixing temperature of $190{ }^{\circ} \mathrm{C}$, the ductility increase again due to decomposition of WTR particles which causing a reduction in binder viscosity. This result is agreement with many of researches as Zanzotto and Kennepohl (1996), Abdelrahman and Carpenter (1999) and Rahman (2004).

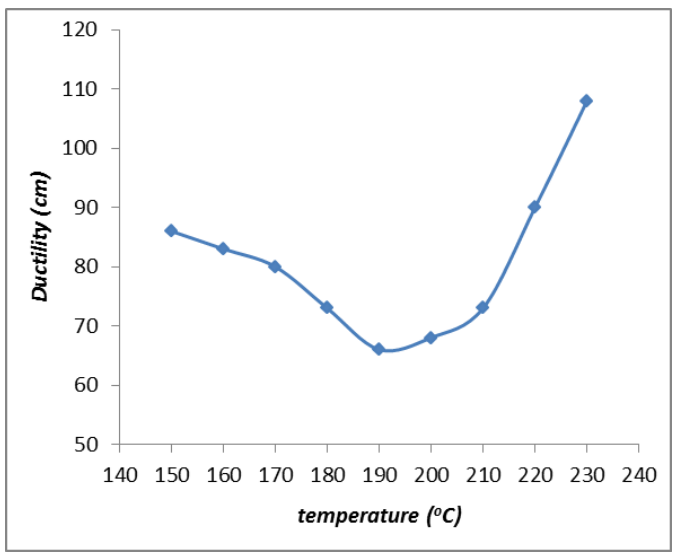

Figure (6) The effect of mixing temperature on ductility.

\section{Conclusion:-}

Based on the experimental work, the following conclusions can be drawn regarding the improving of asphalt binder:

1- Softening point tend to increase with increasing of adding WTR, which indicates improvements in resistance to deformation.

2- Penetration and Ductility at $25^{\circ} \mathrm{C}$ were decreased as increase of WTR content, which indicate an improvement of shear resistance.

3- The experimental data show the WTR seem to improve viscosity and elastic properties of binder which are important to reduce of rutting and shoving that may be happened in the road. The optimum weight percent of addition was $20 \mathrm{wt} \%$.

4- Mixing temperature affected positively at a range of (150-190) ${ }^{\circ} \mathrm{C}$, after that the chains of WTR particles are decomposed as a result of high temperature causing a reduction in binder viscosity. 


\section{References:-}

1. Xiang S. and Baoshan H., (2013), Recycling of Waste Tire Rubber in Asphalt and Portland Cement Concrete: An Overview, Construction and Building Materials.

2. Al-Hadidy A. I., (2006), Evaluation of Pyrolysis Polypropylene Modified Asphalt Paving Materials, AlRafidain Engineering, vol. 14, No. 2, pp. 36-50.

3. Falak O. A., Mohammed O. A. and Ragad O. A., (2009), Optimization of Asphalt MixImproved by the Addition of Scrap Tires, Eng.\& Tech. J., vol. 27, No. 12, pp. 2425-2446.

4. Saad I. S. and Ibtihal M. L., (2014),Assessment of Modification-Asphalt Cement Properties, J. of Engineering, vol. 20, No. 6, pp. 1-13.

5. Zanzotto L. and Kennepohl G., (1996), Development of Rubber and Asphalt Binders by Depolymerization and Devulcanization of Scrap Tires in Asphalt, Trans. Res. Board, vol. 1530, No. 1, pp. 51-58.

6. Abdelrahman M. A. and Carpenter S. H., (1999), The Mechanism of the Interaction of Asphalt Cement with Crumb Rubber Modifier (CRM), Transport Res. Rec., pp. 106-13.

7. Rahman M. M., (2004), Characterization of Dry Process Crumb Rubber Modified Asphaltmixtures,PhD Thesis, University of Nottingham, School of CivilEngineering.

8. Taher M.A., Khalil T. A., Thamer J. A. and Salim M.A., (2009), Study the Effect of Epoxy Additives on Some Physical Properties of Asphalt Cement, J. of Al-Anbar university for pure science, vol.3, No.1.

9. Eman I. M., AdilK. H. and Niam M. A., (2011), Evaluation of the Properties and Storage Stability of EVA Polymer Modified Asphalt,J. of Edu.\& Sci.,vol.24, No. 3,pp. 14-20.

10. Davide L. P., (2013), Recycled Tyre Rubber Modified Bitumens for Road Asphalt Mixtures: Aliterature Review, Construction and Building Materials, vol. 49, pp. 863-881. 